\title{
Combat Sport Nutrition: A Pragmatic Case Study in an Elite Mixed Martial Arts Athlete
}

\author{
Joseph J Matthews ${ }^{1,2}$ \\ 1Sport, Health and Performance Enhancement (SHAPE) Research Centre, Musculoskeletal Physiology Research Group, \\ School of Science and Technology, Nottingham Trent University, United Kingdom. \\ ${ }^{2}$ Research Centre for Life and Sport Sciences (CLaSS), School of Health and Life Sciences, Department of Sport and \\ Exercise, Birmingham City University, United Kingdom.
}

\begin{abstract}
Introduction: Mixed martial arts (MMA) athletes typically undergo energy restriction and severe dehydration to compete in a specific weight category: a process known as making weight. This can pose a health risk to athletes and has led to fatalities. Some risks can be mitigated with structured sports nutrition. Methods: This case study provides an overview of a 10-week sports nutrition intervention devised to support an elite male MMA athlete for a world lightweight title bout. Results: Over a 9-week period, body mass was reduced from $81.6 \mathrm{~kg}$ (baseline) to $75.4 \mathrm{~kg}$ (1-week pre-competition): total loss $6.2 \mathrm{~kg}(8.2 \%)$ equivalent to $0.68 \mathrm{~kg} \cdot \mathrm{wk}^{-1}$. In the final 5 days, body mass was reduced by a further $5.2 \mathrm{~kg}$ (7.4\%), before regaining $5.8 \mathrm{~kg}(8.3 \%)$ and entering competition at $76 \mathrm{~kg}$. There was no incidence of injury or illness throughout the training camp and the athlete reported positive feedback regarding health, wellbeing, and physical performance. Conclusions: The intervention demonstrates a pragmatic approach to making weight by allowing moderate rapid weight loss (RWL) and rapid weight gain under controlled conditions. In the absence of rule changes to prevent RWL, coaches and athletes can utilise sports nutrition strategies to minimise the risks associated with a traditional approach to making weight.
\end{abstract}

Key Words: Making weight; weight cutting; performance; MMA.

DOI: https://doi.org10.31236/osf.io/bgnst.

Citation: Matthews, J.J. (2020). Combat Sport Nutrition: A Pragmatic Case Study in an Elite Mixed Martial Arts Athlete. SportRxiv. doi:10.31236/osf.io/bgnst.

Corresponding author: Joseph J Matthews, joseph.matthews@bcu.ac.uk,@JoeJohnMatthews

Author agreement statement: I, the author, agree to the sharing of this preprint on SportRxiv. 


\section{Introduction}

Mixed martial arts (MMA) is a full contact combat sport in which athletes compete in specific weightcategories. Most athletes, however, compete in a weight category that is incompatible with their habitual (or 'walk around') body mass, meaning they must reduce their body mass for each bout [1]. This process, colloquially referred to as 'making weight', contains three distinct phases: (1) gradual weight loss (GWL) over the weeks preceding competition; (2) rapid weight loss (RWL) in the final $\leq 7$ days; and (3) rapid weight gain (RWG) in the period between the official weigh-in and the start of competition (ranging from 0 to 32 hours). The overall aim is to compete heavier than at the official weigh-in, which may lead to a size and strength advantage over a smaller or lighter opponent [2].

Although making weight is ubiquitous across combat sports, MMA athletes undergo the greatest changes in body mass for competition [3,4]. Kasper et al. [5] followed an MMA athlete who lost 18.1\% $(14.5 \mathrm{~kg})$ body mass over eight weeks; including a reduction of $9.3 \%(7.3 \mathrm{~kg})$ in the final 24-hours, which induced blood values consistent with hypernatremia and acute kidney injury. While extreme, this case not unique and MMA has experienced two RWL-related fatalities in recent years [4]. Both were associated with severe dehydration achieved via potentially harmful methods such as sauna use, training in sweat (rubber) suits, and use of diuretics: all commonly used RWL methods in MMA [6]. Even when RWL is more conservative (e.g., $\sim 5 \%$ body mass), energy restriction and dehydration can acutely increase the risk of infection and injury $[7,8]$. It is clear that making weight carries several actual and potential health risks.

In the absence of rule changes to prevent harmful RWL, we need a pragmatic approach to making weight that meets athlete expectations [10] and allows controlled RWL and RWG with minimal dehydration [9]. This case study provides a structured, evidence-based sports nutrition approach to making weight in an elite MMA athlete. In conjunction with the athlete support team (head coach, technical coaches, and strength and conditioning coach) we aimed to (1) support the athlete to make weight safely, (2) minimise the risk of injury and illness during the training camp; and (3) aid recovery to support multiple training sessions per day.

\section{Athlete Background}

The athlete was a 32-year-old male professional mixed martial artist competing in the lightweight (70.3 $\mathrm{kg} / 155 \mathrm{lbs}$.) category. He was formerly a British K1 champion and turned professional in MMA at the age of 27. Prior to the competition, he held a professional MMA record of 5-1-0 (wins-loss-draw). His last five bouts were at welterweight $(77.1 \mathrm{~kg} / 170 \mathrm{lbs}$.) and he had not competed in the lightweight category since his first professional bout in 2014. The athlete was in good health and had a medical review with his doctor prior to starting the training camp. 
The prospective bout was for the world lightweight title of an international MMA promotion; consisting of $5 \times 5$-minute rounds interspaced by one-minute rest intervals. The first nine weeks of preparation took place in the United Kingdom, following which the athlete travelled to South Africa for the final nine days. The official weigh-in was 11:00-12:00 the day before the bout, with the bout scheduled for 22:00, leaving approximately 31-32 hours for recovery and RWG.

This was the first time the athlete had worked with a Sports Nutritionist. Previously, he adopted a "clean eating" approach (e.g., a grilled lean protein source, with dry seasoning and rice at every meal) with "cheat meals" each weekend. Bouts at welterweight were closer to his walk-around body mass, meaning that RWL was accomplished with only moderate dehydration. The athlete provided informed consent and supported publication of this case study.

\section{Athlete Assessment}

The athlete was interviewed in the first week of fight camp to ascertain his training and nutrition history. Body composition was assessed via bioelectrical impedance analysis (BIA; seca mBCA515, Birmingham, UK) and by recording girths, and skinfolds (measured by an ISAK Level 1 certified anthropometrist) using the Harpenden Caliper (Baty International, West Sussex, UK). These methods were preferred due to economical and practical reasons. The athlete recorded body mass daily—nude, upon waking, after first morning void—and uploaded it to a cloud-based spreadsheet.

Resting metabolic rate (RMR) was estimated using the seca mBCA515 and cross-referenced with the Cunningham [11] prediction equation. Results of the baseline assessment are shown in Table 1. A major challenge of sports nutrition practice is quantifying energy expenditure; we used physical activity ratios as an estimate for each activity across each day and a typical week [12]. This provided an average daily physical activity ratio of $1.95 \times$ RMR (Table 1), which was used as an approximation for the initial diet. Total training volume was $\sim 21$ hours per week, split across six days, which reduced to $\sim 10$ hours per week in the RWL phase.

\section{Sports Nutrition Intervention}

Following baseline assessment, the athlete received an individualised meal plan tailored to his food likes and dislikes (Table 2). We planned a GWL of $6.4 \mathrm{~kg}(8.5 \%)$ over the first nine weeks of the training camp: achieved via increased physical activity levels and moderate calorie restriction. This would leave $4.9 \mathrm{~kg}(7 \%)$ of body mass to reduce in the RWL phase. Considering the athletes previous RWL practices, we felt a target of $\leq 7 \%$ RWL was a realistic compromise i.e., it could be achieved in a controlled manner without adverse 
health effects, whilst meeting the athletes expectations for RWG that he felt would be advantageous in competition.

Table 1. Overview of athlete characteristics at baseline.

\begin{tabular}{lc}
\hline Characteristic & Value \\
\hline Age & 32 years \\
Height & $1.77 \mathrm{~m}$ \\
Baseline Body Mass & $81.6 \mathrm{~kg}$ \\
Body Fat & $15.5 \%$ \\
Fat Mass & $12.7 \mathrm{~kg}$ \\
Fat Free Mass & $68.9 \mathrm{~kg}$ \\
Muscle Mass & $34.7 \mathrm{~kg}$ \\
Resting Metabolic Rate & \\
\multicolumn{1}{c}{ Seca mBCA515 } & $1806 \mathrm{kcal} \cdot \mathrm{day}^{-1}$ \\
$\quad$ Cunningham equation & $2016 \mathrm{kcal} \cdot \mathrm{day}^{-1}$ \\
Total Daily Energy Expenditure & \\
$\quad$ Seca mBCA515 x 1.95 & $3522 \mathrm{kcal}^{-d a y^{-1}}$ \\
Sum of Eight Skinfolds & $82.6 \mathrm{~mm}$ \\
Waist Girth & $81.3 \mathrm{~cm}$ \\
Gluteal Girth & $98.5 \mathrm{~cm}$ \\
\hline
\end{tabular}

The dynamic weight loss model estimated $\sim 900 \mathrm{kcal}^{-d a y^{-1}}$ deficit to achieve the target GWL [13]. While only an approximation the tool is more precise than the widely used Wishnofsky rule [14], which overestimates the amount of weight loss over time. We adjusted the plan as necessary throughout the training camp by gradually reducing energy and carbohydrate intake. Example daily intake two weeks precompetition: $2000 \mathrm{kcal}, 160 \mathrm{~g}$ protein, $160 \mathrm{~g}$ carbohydrate, and 80g dietary fat. Energy intake was kept above RMR until the RWL phase. Meal plans were composed and analysed using commercially available dietary analysis software (Nutritics, Version 5.09, Dublin, Ireland).

Daily protein intake was set at $\sim 2.2 \mathrm{~g} \cdot \mathrm{kg} \cdot \mathrm{day}^{-1}$ to preserve lean body mass during the GWL phase [15], and included leucine-rich protein sources (e.g., dairy, chicken, turkey, beef) for their potentiating effect on

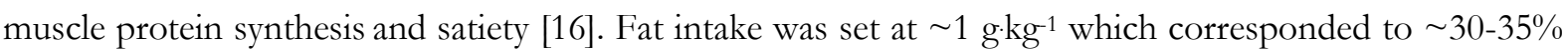
of total energy intake. This was chosen as it suited the athlete's food and taste preferences; furthermore, dietary fat intake $>20 \%$ may help maintain circulating anabolic hormone levels when dieting [17]. During the GWL phase, water was consumed ad libitum throughout the day (total $\sim 3-4 \mathrm{Lday}^{-1}$ ) with $\sim 500 \mathrm{~mL}$ consumed in the 30 minutes prior to each training session. 
Table 2. A representative day of nutrition 9 weeks pre-competition.

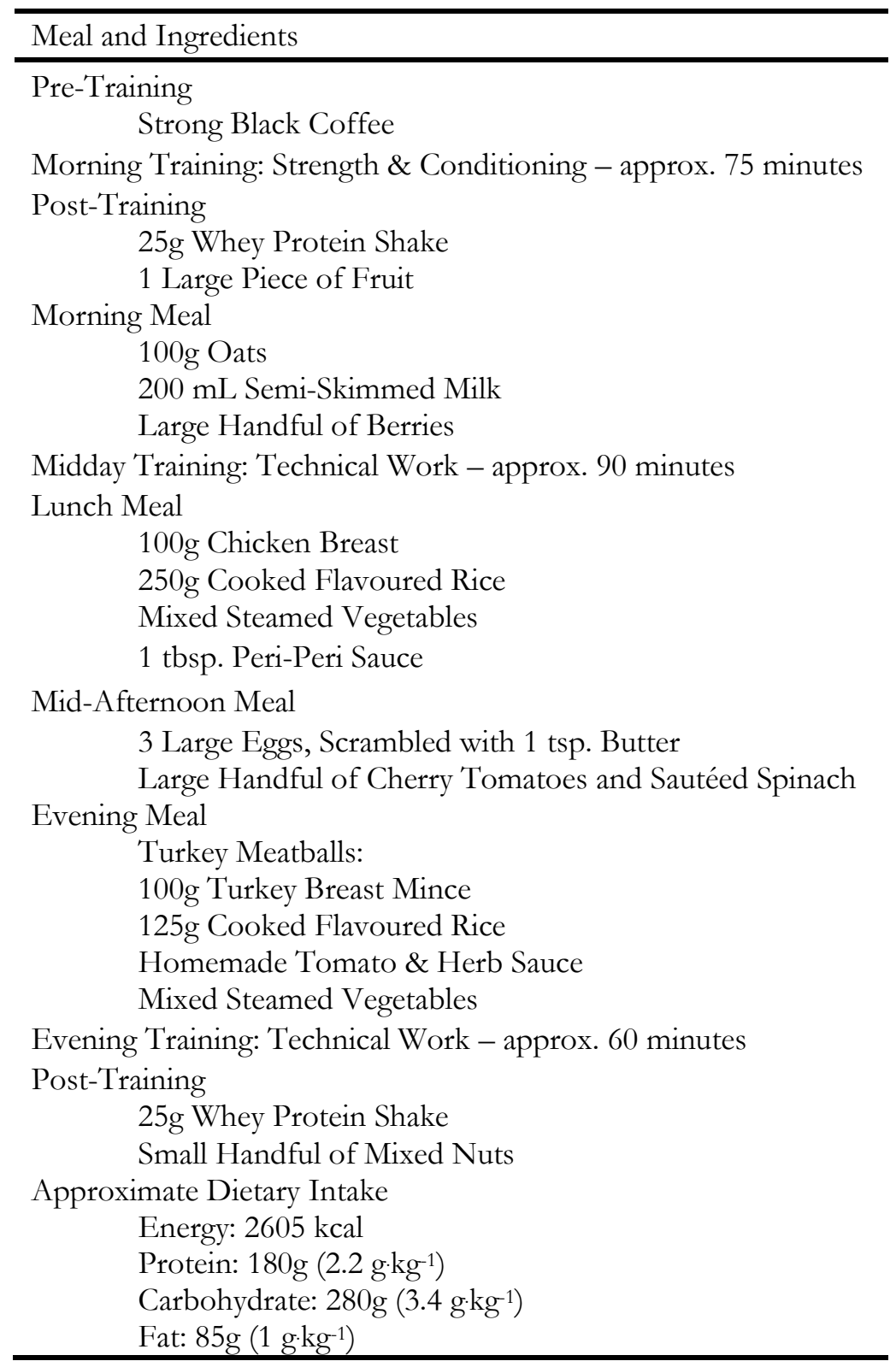

Due to the energy restriction, carbohydrate intake was insufficient to maximise physical performance in every training session. Instead we periodised carbohydrate intake, adopting a 'sleep low, train low' approach (Table 2) in which carbohydrates were restricted after the evening training session; and prior to the morning training session [18]. This allowed for a higher carbohydrate intake to promote glycogen resynthesis for the midday and evening training sessions.

To enhance compliance and offset some of the negative consequences of prolonged calorie-restriction, a carbohydrate refeed was planned every $\sim 14$ days during the GWL phase [19]. This consisted of one day (typically Saturday or Sunday) at maintenance calories with a higher carbohydrate intake ( $\sim 75-80 \%$ of total energy intake). 
Rapid weight loss was achieved using a range of sports nutrition methods [9]: calorie-restriction, glycogen depletion ( $<30 \mathrm{~g}^{\text {day }}{ }^{-1}$ carbohydrate for final 3 -days), gut content manipulation $\left(<10 \mathrm{~g}^{-d_{a y}}{ }^{-1}\right.$ fibre for the final 2-days), and a modified water loading protocol $\left(7 \mathrm{Lday}^{-1}\right.$ for 3-days followed by $1.25 \mathrm{Lday}^{-1}$ on the day before the weigh-in). Due to the potential risk for hyponatremia and gastrointestinal distress, water intake was spread evenly throughout the day $(\sim 500 \mathrm{~mL}$ per hour) during the loading phase. On the final morning the athlete was nil by mouth until the official weigh-in.

During the RWG phase, the athlete consumed $12 \mathrm{~g}^{\mathrm{kg}}{ }^{-1}$ carbohydrate: $\sim 8 \mathrm{~g} \mathrm{~kg}^{-1}$ on the weigh-in day and 4 $\mathrm{g} \cdot \mathrm{kg}^{-1}$ on the day of competition. The aim was to restore muscle and liver glycogen, so fat and protein intake were kept low ( $\sim 10 \%$ and $\sim 15 \%$ of total energy intake, respectively). Rehydration was achieved via structured consumption of carbohydrate and electrolyte-containing drinks in the first 2-hours post weighin (fruit juices, rehydration drinks, and coconut water), following which the athlete consumed fluids ad libitum. Food intake on competition day was tailored to make the athlete feel comfortable, with the final meal containing $\sim 1.2 \mathrm{gkg}^{-1}$ carbohydrate and consumed $\sim 3$-hours prior to the warm-up.

During the first eight weeks, the diet was supplemented with whey concentrate protein powder, milk protein bars (Grenade ${ }^{\circledR}$, Solihull, United Kingdom), vitamin D3 (1000 IU·day ${ }^{-1}$ ), and isotonic sports drinks (for carbohydrate mouse rinsing). For the final two weeks, the athlete also consumed beta-hydroxy-betamethylbutyrate (HMB) (3 g.day $\left.{ }^{-1}\right)$ with vitamin B6, and zinc lozenges (providing 10mg ionic zinc per lozenge) 2-3 times per day. Following the weigh-in, the athlete consumed a protein-carbohydrate-electrolyte recovery drink (Science in Sport, London, United Kingdom). All supplements were batch-tested and sourced from Healthspan Elite (Guernsey, United Kingdom) unless otherwise stated.

\section{Outcome of the Intervention}

Figure 1 depicts the changes in body mass throughout the training camp. Over a 9-week period, body mass was reduced from $81.6 \mathrm{~kg}$ (baseline) to $75.4 \mathrm{~kg}$ (1-week pre-competition): total loss $6.2 \mathrm{~kg}(8.2 \%)$ equivalent to $0.68 \mathrm{~kg} \mathrm{wk}^{-1}$. This reduction was slightly below our initial predictions (target RWL $\leq 7 \%$ ), which meant we had to accommodate a larger amount of RWL $(\sim 5.1 \mathrm{~kg}[7.3 \%])$ in competition week.

In the final five days, body mass was reduced by $5.2 \mathrm{~kg}(7.4 \%)$ and the athlete weighed $70.2 \mathrm{~kg}$ at the official weigh-in: $0.1 \mathrm{~kg}$ below the weight category limit. Body mass was higher than planned on the evening before the weigh-in and the athlete decided to undergo a short bout ( $\sim 20$ mins) of passive dehydration (hot bath) to induce a loss of $\sim 1.5 \%(\sim 1 \mathrm{~kg})$ body mass. This was performed under the guidance of the support team who monitored him throughout. During the 31-hour recovery period, the athlete regained $5.8 \mathrm{~kg}(8.3 \%)$ and entered competition at $76 \mathrm{~kg}$. He won the bout by unanimous decision. 


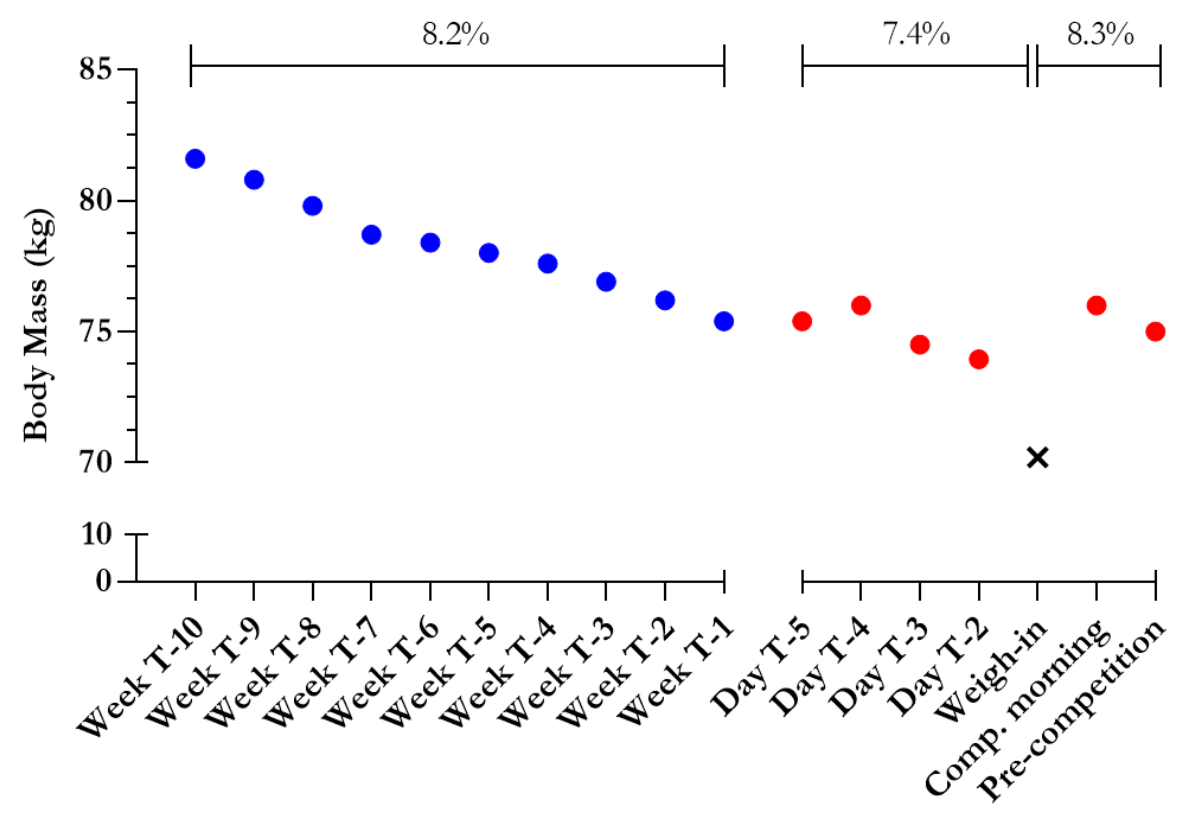

Figure 1. Change in body mass across the three main phases: (1) gradual weight loss; (2) rapid weight loss; and (3) rapid weight gain. Blue circles show the average weekly body mass, red circles show daily body mass during competition week, and the black cross is the official weigh-in body mass. The final body mass was recorded $\sim 1$-hour before competition.

Due to overseas travel, we were unable to re-measure body composition in the final 10 days. When measured two weeks pre-competition (body mass $76.2 \mathrm{~kg}$, fat mass $8.4 \mathrm{~kg}$ [11\%], fat free mass $67.8 \mathrm{~kg}$ ) body mass losses were primarily from fat mass $(-4.3 \mathrm{~kg})$ with smaller reductions in fat free mass $(-1.1 \mathrm{~kg})$. These changes should be interpreted with the knowledge that the seca mBCA515 underestimates changes in fat mass when compared to dual energy x-ray absorptiometry [20].

Throughout the intervention, the athlete reported feeling "stronger", "fitter", and "more powerful" compared to previous training camps, and despite the large energy deficit, the athlete reported no symptoms of illness, overtraining, or those associated with relative energy deficiency in sport (RED-S) [21].

\section{Discussion and Summary}

As a Sports Nutritionist working in MMA, there can be an ethical dilemma between supporting athletes to make weight safely and acquiescence with their use of potentially harmful RWL practices. This case study shows a pragmatic approach, whereby RWL (7.4\%) can be achieved with only mild passive dehydration $(\sim 3.5 \%)$ and without the use of harmful methods. The total body mass loss of $11.4 \mathrm{~kg}(14 \%)$ over 10 -weeks was possible due to careful planning and diligence of the athlete and his support team. Had the athlete 
planned to compete at featherweight $(65.8 \mathrm{~kg} / 145 \mathrm{lbs}$.) the required GWL would be insurmountable, leaving RWL ( $\geq 10 \%)$ that could only be achieved with substantial dehydration.

While it is difficult to quantify the impact of each strategy, we estimate the 7.4\% RWL occurred via the following losses: energy deficit $(\sim 1 \%)$, glycogen depletion $(\sim 2 \%)$, fibre restriction $(\sim 1 \%)$, water loading $(\sim 1 \%)$, passive sweating $(\sim 1.5 \%)$, and short-term fluid restriction $(\sim 1 \%)$. This approach to RWL can only be successful if the athlete enters the final week in a hydrated and well-nourished state. Many athletes may already be glycogen depleted and have little gut content to manipulate, putting themselves at risk due to an increased reliance on dehydration methods. In addition, the day before weigh-in allowed ample time ( $\sim 31$ hours) to refuel and rehydrate. For events where the weigh-in is closer to competition, the limit of safe RWL will be lower due to inadequate recovery time before competition [9].

Despite being hypocaloric on every training day, the athlete reported he was able to train "more" and "harder" than in previous training camps. Many aspects of the intervention were new to him and possible explanations include: (1) use of carbohydrate mouse-rinsing and caffeine before each morning training session to aid performance when carbohydrate availability is low [22]; (2) maximising carbohydrate availability for the midday and evening training sessions [18]; (3) preservation of lean body mass by virtue of a higher protein intake [15]; and (4) maintenance of energy intake above RMR until the final week [23].

One limitation is the absence of renal function and blood electrolyte data to determine the clinical safety of the intervention. However, while passive dehydration of $\sim 3-4 \%$ body mass induces a modest increase in hematocrit $(\sim 3 \%)$ and serum osmolality $\left(\sim 9 \mathrm{mOsm} \cdot \mathrm{kg}^{-1}\right)$, it can be reversed with a short period ( $\sim$-hours) of refueling and rehydration [24] and is considered a safe method for modeling dehydration [25]. As an additional precaution, the athlete distributed water intake (during water loading) evenly throughout the day $\left(\sim 500 \mathrm{~mL}^{-1}\right)$ and kept the rate of intake below the peak urine flow rate $\left(\sim 600\right.$ to $\left.900 \mathrm{~mL}^{-1}\right)$ [26]. Failure to do this may mean that water intake is not compensated by urine output, which can lead to hyponatremia and, in severe cases, death [27]. Weight-category athletes using water loading as an RWL strategy should be mindful of these risks.

This case study shows a pragmatic sports nutrition approach that we deemed effective for three reasons: (1) the athlete made weight safely without any reported adverse effects; (2) there were no reported symptoms of illness or injury during training camp; and (3) subjective feedback of performance, recovery and wellness were positive throughout. In the absence of rule changes to prevent RWL, coaches and athletes can utilise sports nutrition strategies to minimise the risks associated with a traditional approach to making weight. 


\section{Acknowledgements}

The author would like to acknowledge the hard work of the athlete and the support team.

\section{References}

1. Artioli GG, Saunders B, Iglesias RT, Franchini E. It is time to ban rapid weight loss from combat sports. Sports Medicine. 2016;46(11):1579-84.

2. Langan-Evans C, Close GL, Morton JP. Making weight in combat sports. Strength \& Conditioning Journal. 2011;33(6):25-39.

3. Barley OR, Chapman DW, Abbiss CR. Weight loss strategies in combat sports and concerning habits in mixed martial arts. International journal of sports physiology and performance. 2018;13(7):933-9.

4. Matthews JJ, Stanhope EN, Godwin MS, Holmes ME, Artioli GG. The magnitude of rapid weight loss and rapid weight gain in combat sport athletes preparing for competition: A systematic review. Int J Sport Nutr Exer Metab. 2019;29(4):441-52.

5. Kasper AM, Crighton B, Langan-Evans C, Riley P, Sharma A, Close GL, Morton JP. Case Study: Extreme Weight Making Causes Relative Energy Deficiency, Dehydration, and Acute Kidney Injury in a Male Mixed Martial Arts Athlete. International journal of sport nutrition and exercise metabolism. 2019;29(3):331-8.

6. Hillier M, Sutton L, James L, Mojtahedi D, Keay N, Hind K. High Prevalence and Magnitude of Rapid Weight Loss in Mixed Martial Arts Athletes. International journal of sport nutrition and exercise metabolism. 2019;29(5):512-517.

7. Green CM, Petrou MJ, Fogarty-Hover ML, Rolf CG. Injuries among judokas during competition. Scandinavian journal of medicine \& science in sports. 2007;17(3):205-10.

8. Tsai ML, Chou KM, Chang CK, Fang SH. Changes of mucosal immunity and antioxidation activity in elite male Taiwanese taekwondo athletes associated with intensive training and rapid weight loss. British journal of sports medicine. 2011;45(9):729-34.

9. Reale R, Slater G, Burke LM. Individualised dietary strategies for Olympic combat sports: Acute weight loss, recovery and competition nutrition. European Journal of Sport Science. 2017;17(6):727-40.

10. Pettersson S, Ekström MP, Berg CM. Practices of weight regulation among elite athletes in combat sports: a matter of mental advantage?. Journal of Athletic Training. 2013;48(1):99-108.

11. Cunningham JJ. A reanalysis of the factors influencing basal metabolic rate in normal adults. Am J Clin Nutr. 1980;33(11):2372-4.

12. World Health Organization (WHO). Human energy requirements: report of a joint/FAO/WHO/UNU expert consultation. 2004. Accessed on December 10, 2019 from: www.who.int/nutrition/publications/nutrientrequirements/9251052123/en/.

13. Hall KD, Sacks G, Chandramohan D, Chow CC, Wang YC, Gortmaker SL, Swinburn BA. Quantification of the effect of energy imbalance on bodyweight. The Lancet. 2011;378(9793):826-37. 
14. Wishnofsky M. Caloric equivalents of gained or lost weight. American Journal of Clinical Nutrition. 1958;6:542-6.

15. Mettler S, Mitchell N, Tipton KD. Increased protein intake reduces lean body mass loss during weight loss in athletes. Medicine \& Science in Sports \& Exercise. 2010;42(2):326-37.

16. Tipton KD. Efficacy and consequences of very-high-protein diets for athletes and exercisers. Proceedings of the Nutrition Society. 2011;70(2):205-14.

17. Helms ER, Aragon AA, Fitschen PJ. Evidence-based recommendations for natural bodybuilding contest preparation: nutrition and supplementation. Journal of the International Society of Sports Nutrition. 2014;11(1):20.

18. Impey SG, Hearris MA, Hammond KM, Bartlett JD, Louis J, Close GL, Morton JP. Fuel for the work required: a theoretical framework for carbohydrate periodization and the glycogen threshold hypothesis. Sports Medicine. 2018;48(5):1031-48.

19. Peos JJ, Norton LE, Helms ER, Galpin AJ, Fournier P. Intermittent dieting: theoretical considerations for the athlete. Sports. 2019;7(1):22.

20. Day K, Kwok A, Evans A, Mata F, Verdejo-Garcia A, Hart K, Ward L, Truby H. Comparison of a Bioelectrical Impedance Device against the Reference Method Dual Energy X-Ray Absorptiometry and Anthropometry for the Evaluation of Body Composition in Adults. Nutrients. 2018;10(10):1469.

21. Burke LM, Close GL, Lundy B, Mooses M, Morton JP, Tenforde AS. Relative energy deficiency in sport in male athletes: A commentary on its presentation among selected groups of male athletes. International journal of sport nutrition and exercise metabolism. 2018;28(4):364-74.

22. Kasper AM, Cocking S, Cockayne M, Barnard M, Tench J, Parker L, McAndrew J, Langan-Evans C, Close GL, Morton JP. Carbohydrate mouth rinse and caffeine improves high-intensity interval running capacity when carbohydrate restricted. European Journal of Sport Science. 2016;16(5):560-8.

23. Logue D, Madigan SM, Delahunt E, Heinen M, Mc Donnell SJ, Corish CA. Low energy availability in athletes: a review of prevalence, dietary patterns, physiological health, and sports performance. Sports Medicine. 2018;48(1):73-96.

24. Barley OR, Chapman DW, Marvopalais G, Abbiss CR. The Influence of Heat Acclimation and Hypohydration on Post-Weight-Loss Exercise Performance. International Journal of Sports Physiology and Performance. 2019;1:1-26.

25. Cheuvront SN, Kenefick RW. Dehydration: physiology, assessment, and performance effects. Comprehensive Physiology. 2011 Jan 17;4(1):257-85.

26. Kamel KS, Halperin ML. Polyuria. In: Fluid, electrolyte and acid-base physiology (5 $5^{\text {th }}$ edition): a problem-based approach. Elsevier Health Sciences; 2017.

27. Adrogué HJ, Madias NE. Hyponatremia. New England Journal of Medicine. 2000;342(21):1581-9. 